RECENT ADVANCES

\title{
Current treatment and prognosis in children with functionally univentricular hearts
}

\author{
R Kaulitz, M Hofbeck
}

Arch Dis Child 2005;90:757-762. doi: 10.1136/adc.2003.034090

For more than 30 years Fontan-type procedures have been performed for surgical treatment in patients with functionally univentricular hearts. Advances in proper patient selection, staging of the Fontan palliation, and modifications of the surgical technique resulted in continuous improvement of the surgical results during the past two decades. However, increasing experience with medium term and long term follow-up of the Fontan circulation has drawn attention to a number of sequelae and chronic complications affecting a significant number of patients.

See end of article for authors' affiliations

.....................

Correspondence to: Prof. Dr M Hofbeck, Department of Pediatric Cardiology and Pediatric Intensive Care Medicine, Tuebingen University Hospital, Hoppe-Seyler Str.3, D-72076 Tuebingen, Germany;

michael.hofbeck@med. uni-tuebingen.de

Accepted

14 February 2005 $\mathrm{n}$ this review we will discuss the current surgical management of patients with functionally univentricular hearts, postoperative haemodynamics, and long term sequelae of the univentricular circulation.

\section{ANATOMY}

Nearly $10 \%$ of congenital heart defects belong to the group of functionally univentricular hearts. The natural history of the vast majority is characterised by a fatal course in the neonatal period or in early infancy. Only a few patients with an optimal balance between pulmonary and systemic circulation may survive into adulthood without surgical intervention. ${ }^{1}$

Patients with functionally univentricular hearts represent a heterogeneous group of cardiac malformations almost always determined by a dominant ventricle of either left or right ventricular morphology. The following are the most common subtypes of functionally univentricular hearts. The ventricle may present with univentricular atrioventricular connection; the two atrioventricular valves drain into a dominant pumping ventricle of usually left ventricular morphology as in patients with double inlet ventricle (fig 1A). A second group includes patients with absence or severe stenosis of either the right or left atrioventricular connection almost always associated with severe hypoplasia of the corresponding ventricle (for example, patients with tricuspid or mitral atresia, hypoplastic left heart syndrome, or pulmonary atresia with hypoplastic right ventricle) (fig 1B). The third group comprises patients with bilateral atrioventricular connection but either marked hypoplasia of the right or left ventricle or abnormalities of atrioventricular or ventriculoarterial connection precluding a biventricular repair (for example, unbalanced atrioventricular septal defect or complex forms of transposition of the great arteries or double outlet right ventricle) (fig lC).

It is therefore a wide range of congenital heart defects that can be palliated by a modified Fontan operation irrespective of the underlying cardiac malformation and associated anomalies of the systemic venous and pulmonary venous return. $^{23}$

\section{SURGICAL MANAGEMENT IN THE NEONATAL PERIOD AND PRE-FONTAN PALLIATION}

The majority of patients entering the univentricular heart protocol have to undergo various forms of surgical procedures to balance and optimise pulmonary and systemic blood flow. Initial palliations to increase pulmonary blood flow in the presence of severely reduced pulmonary perfusion include aortopulmonary shunt procedures. For children with systemic outflow obstruction or hypoplastic left heart syndrome the Damus-Kaye-Stansel anastomosis and Norwood-type procedures will augment the systemic blood flow while pulmonary blood flow is controlled by an aortopulmonary shunt procedure or a right ventricular-pulmonary artery conduit. ${ }^{45}$ Furthermore, obstructions of the aortic arch, restrictive foramen ovale, and obstructive total anomalous pulmonary venous connections have to be addressed during primary palliation.

In infants with functionally univentricular hearts who have no obstruction to pulmonary outflow, excessive pulmonary blood flow might develop as pulmonary resistance falls in the first weeks of life. In this situation restriction of pulmonary blood flow can be achieved by surgical creation of a supravalvular stenosis ("pulmonary banding"). However, if obstruction to systemic outflow might develop after reduction of ventricular volume loading pulmonary banding should not be applied; in this situation a Damus-Kaye-Stansel anastomosis should be preferred. ${ }^{67}$

\section{BIPULMONARY GLENN ANASTOMOSIS AND HEMI-FONTAN OPERATION}

One of the major improvements of the last decade resulting in a significant decrease in morbidity and mortality following modified Fontan procedures has been the concept of staging by a preceding bidirectional cavopulmonary anastomosis (Glenn anastomosis) ${ }^{8}{ }^{9}$ (fig 2A). The hemi-Fontan operation differs technically from the bidirectional cavopulmonary anastomosis but offers similar physiology (fig $2 \mathrm{~B}$ ). ${ }^{9}$ 


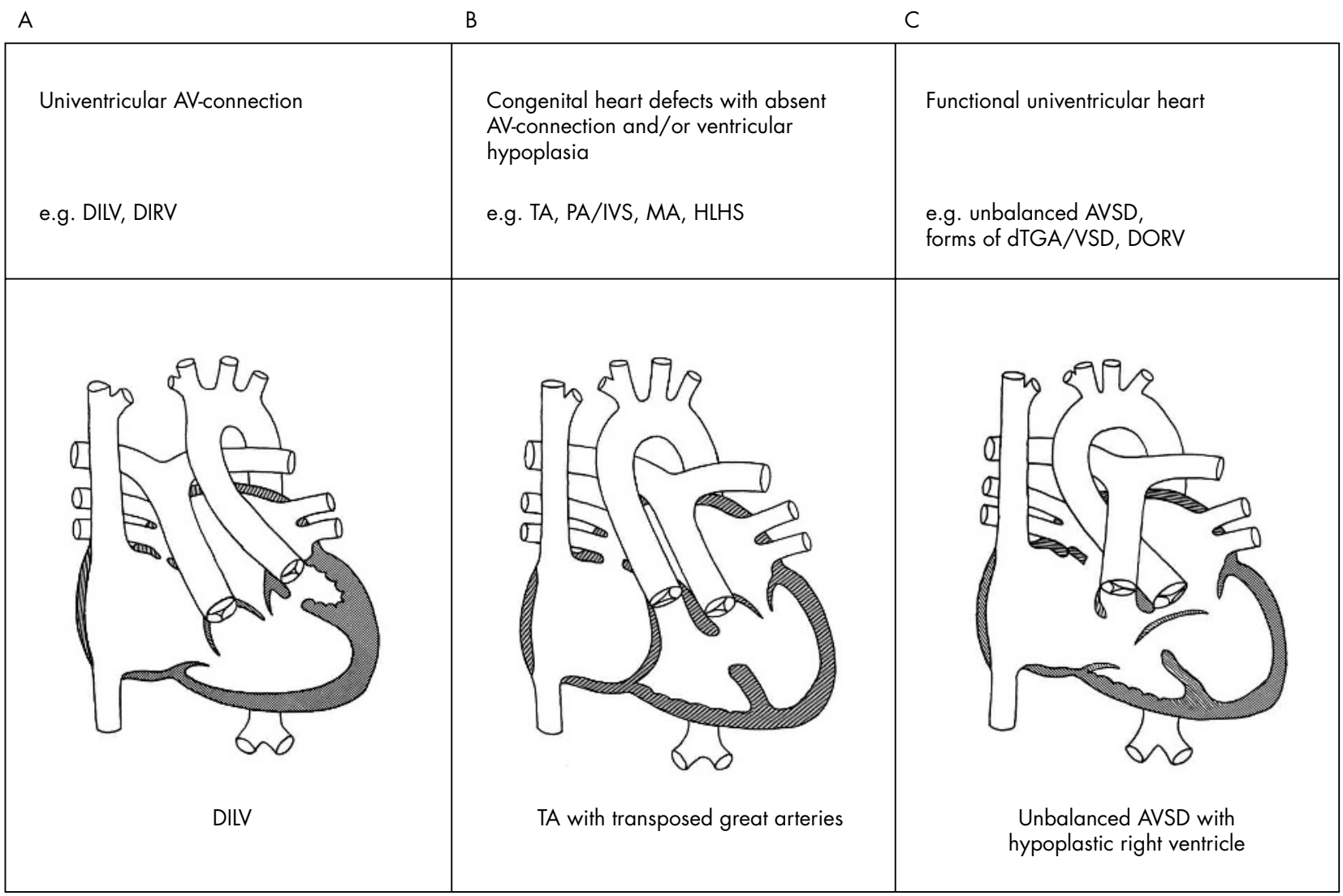

Figure 1 Functional univentricular hearts requiring palliation by Fontan-type procedures as functional correction. DILV, double inlet left ventricle; DIRV, double inlet right ventricle; TA, tricuspid atresie; PA/IVS, pulmonary atresie with intact ventricular septum; MA, mitral atriesia; HLHS, hypoplastic left heart syndrome; AVSD, atrioventricular septal defect; TGA, transposition of the great arteries; DORV, double outlet right ventricle.

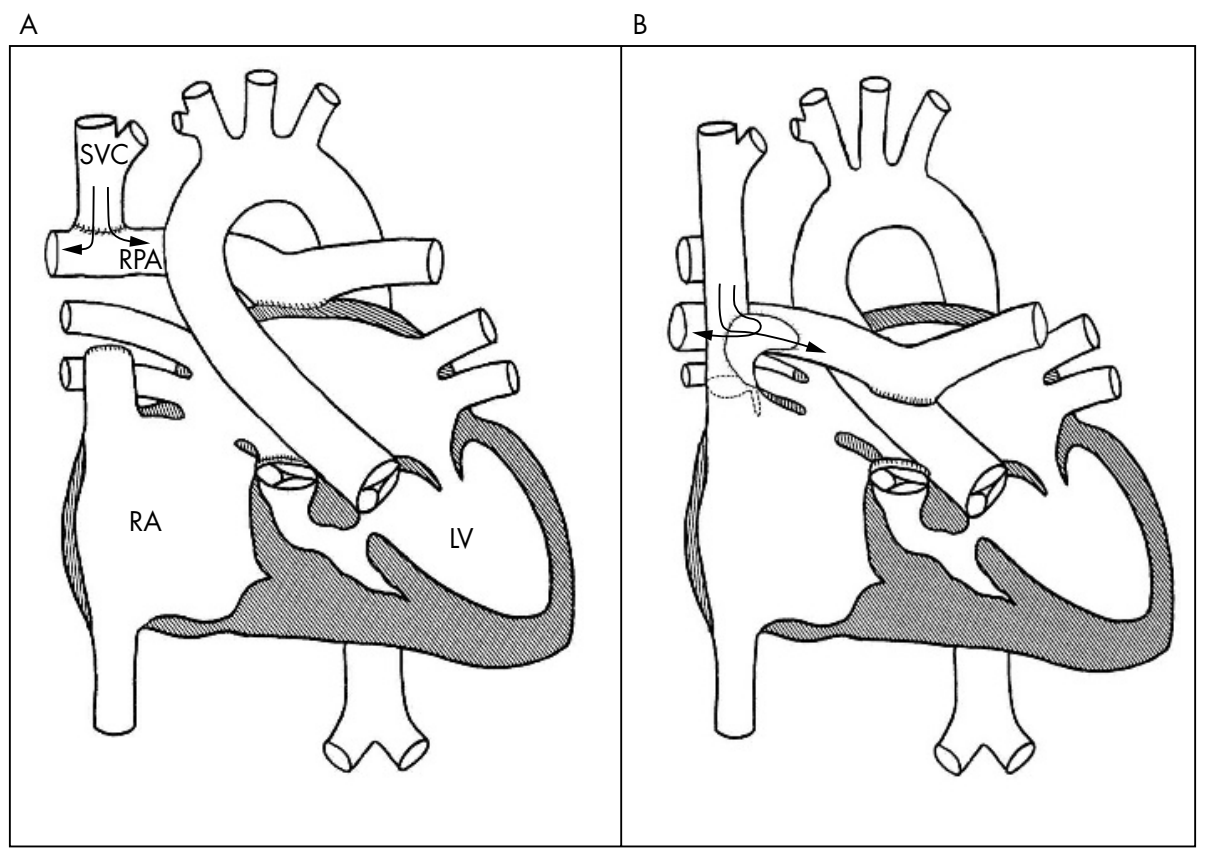

Figure 2 (A) The bidirectional Glenn anastomosis is constructed by disconnecting the main pulmonary artery (oversewn at valvular level), dividing the superior vena cava and connecting the distal superior vena cava to the right pulmonary artery. (B) The hemi-Fontan operation consists of a right atrial to right pulmonary artery anastomosis, the right pulmonary artery is augmented anteriorly with a pulmonary allograft patch to create a wide pathway that conducts blood from the superior vena cava to the pulmonary artery; a portion of the allograft gusset is used to close the junction of the right atrium with the superior vena cava. SVC, superior vena cava; RPA, right pulmonary artery; RA, right atrium; LV, left ventricle. 


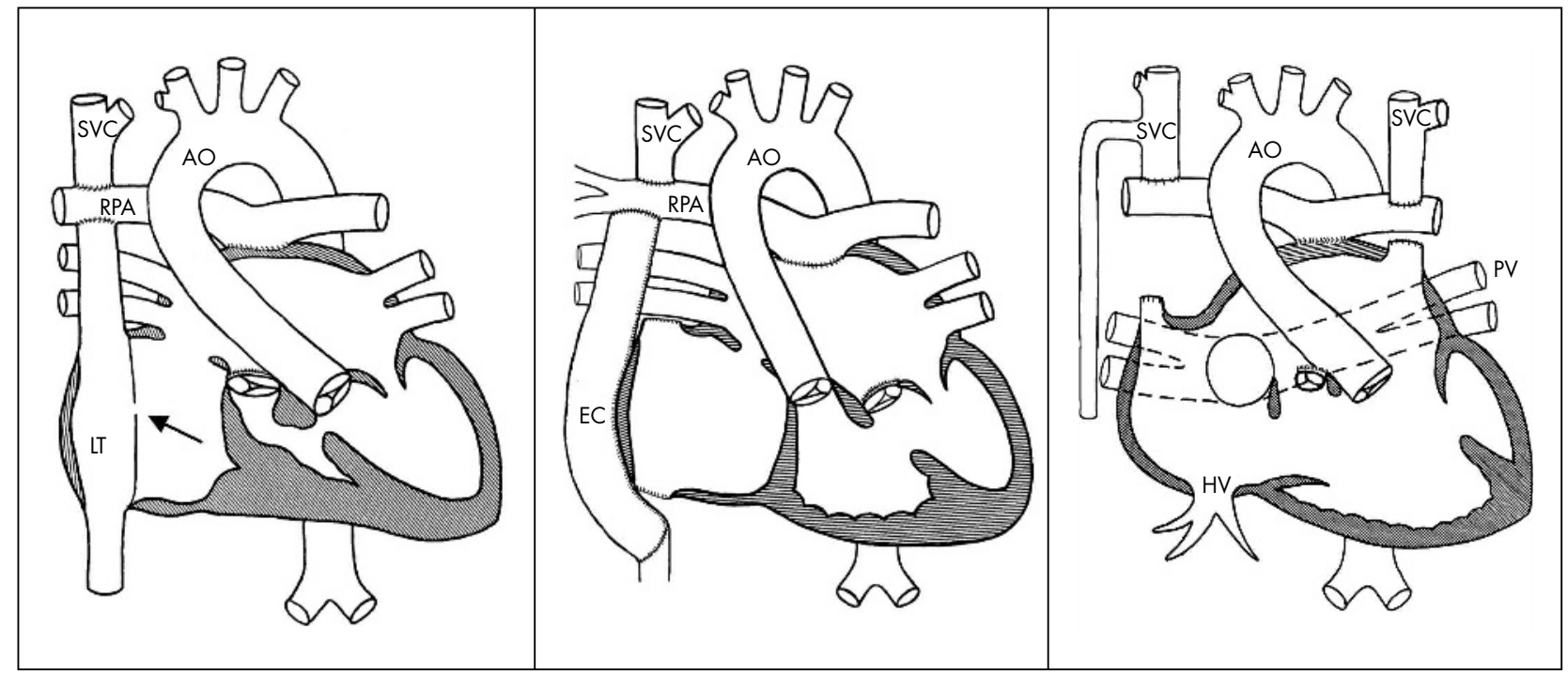

Figure 3 Fontan-type procedures in functionally univentricular hearts. (A) Lateral tunnel procedure with fenestration (arrow). (B) Extracardiac tunnel/ conduit procedure. (C) Kawashima-type operation with bilataral cavopulmonary anastomosis leaving the hepatic venous drainge to the pulmonary venous atrium. SVC, superior vena cava; RPA, right pulmonary artery; AO, aorta; LT, lateral tunnel; EC, extracardiac conduit; HV, hepatic vein; PV, pulmonary vein.

This first step in separating systemic venous return from the heart is aimed at reducing volume loading of the dominant ventricle which is destined to support systemic circulation. Furthermore, at the same time associated anomalies can be addressed, for example pulmonary arterioplasty for pulmonary artery stenosis, correction of unobstructed total anomalous pulmonary venous return, atrioventricular valve plasty for atrioventricular valve regurgitation, and resection of subaortic obstruction. Bidirectional cavopulmonary anastomosis is usually performed between 6 months and 2 years of age and the Fontan operation between 2 and 4 years of age, albeit these age ranges may vary between different surgical centres.

\section{MODIFIED FONTAN PROCEDURES}

Since Fontan and Baudet in $1971^{10}$ introduced the principle of bypassing the right heart by diverting the systemic venous blood directly to the pulmonary arteries, significant modifications of this technique have been developed..$^{11}{ }^{12}$ The initial technique (so-called atriopulmonary anastomosis) included a direct connection of the right (systemic venous) atrium with the central pulmonary arteries. Long term follow up in patients with incorporation of the entire systemic venous atrium in the Fontan circulation, however, revealed a high incidence of postoperative atrial dysrhythmias and thromboembolic events. In 1988 de Leval and associates and Jonas and Castaneda ${ }^{13}{ }^{14}$ developed the technique of total cavopulmonary anastomosis/connection. This technique includes the bidirectional cavopulmonary anastomosis redirecting the blood from the upper body to both pulmonary arteries. In addition an intra-atrial tubular tunnel (so-called "lateral tunnel procedure") reroutes the systemic venous blood from the inferior caval vein to the orifice of the superior caval vein and the cavopulmonary anastomosis. In the majority of cases the lateral tunnel is created by insertion of a semicylindrical polytetrafluorethylene (PTFE) baffle incorporating a small portion of the lateral atrial wall. ${ }^{13-16}$ In some patients the lateral tunnel can be created by autologous material from the interatrial septum. ${ }^{17}$

However, from the beginning of Fontan-type palliation it became clear that proper patient selection is essential for the success of these procedures. ${ }^{18}$ Preoperative selection criteria, although modified during the last years, are still of importance with regard to ventricular function (end diastolic ventricular pressure $<10 \mathrm{~mm} \mathrm{Hg}$ ), mean pulmonary artery pressure $(<15 \mathrm{~mm} \mathrm{Hg})$, and pulmonary vascular resistance $\left(<2.5\right.$ Wood units). ${ }^{1}{ }^{15}{ }^{16}$ Compromised systemic ventricular function, significant atrioventricular valve regurgitation, and associated pulmonary venous anomalies in patients with heterotaxy syndrome were found to increase the postoperative mortality and morbidity. ${ }^{19}$

In a subgroup of patients at increased risk (that is, young age at operation, increased mean pulmonary artery pressure, relevant atrioventricular valve regurgitation, associated systemic or pulmonary venous anomalies) a small fenestration can be created in the intra-atrial tunnel at the time of total cavopulmonary connection to allow a protective right-to-left shunt. The fenestration helps the patient to overcome the period of postoperative low cardiac output by increasing systemic ventricular preload (fig 3A). This modification has improved operative survival rates among high risk patients and shortens duration of pleural effusions and length of hospital stay. ${ }^{19}$ A considerable percentage of small fenestrations will close spontaneously later on. In patients with persistently patent fenestration and mild cyanosis it remains controversial whether later interventional occlusion is required. In patients with increasing cyanosis during exercise transcatheter device occlusion of fenestration is recommended in the presence of appropriate haemodynamics. ${ }^{2021}$ It should not be done in patients with preoperative risk factors (age at operation and preoperative haemodynamics), residual or even mild pulmonary artery distortion or anastomotic stenosis, relevant atrioventricular valve regurgitation, and signs of systemic ventricular dysfunction. ${ }^{22}$

The extracardiac tunnel procedure is the most recent modification of the Fontan procedure. It allows for better preservation of ventricular and pulmonary function because it can be performed with minimal or no cardiopulmonary bypass. In addition the extracardiac tunnel procedure avoids right atrial incisions as well as extensive atrial suture lines. This is supposed to reduce the risk of injury of the sinus node and the incidence of postoperative arrhythmias. If the 
extracardiac tunnel is created either by homograft or conduit (fig 3B) it has no growth potential and is at risk for obstruction by thrombus formation or neointimal hyperplasia. It is limited to patients of a minimum age of about 3 years and weight of about $15 \mathrm{~kg} \cdot{ }^{23-25}$ The use of pedicled pericardium for the extracardiac connection has potential advantages of growth potential and lower risk of thromboembolic complications, but longer follow up periods and comparative studies are required to prove the benefit of either method..$^{24}$

In patients with infrahepatic interruption of the inferior vena cava only the hepatic veins drain into the right atrium. Blood from the lower body reaches the superior caval vein via the azygos vein. In these patients a bidirectional cavopulmonary anastomosis (Kawashima operation) (fig 3C) will result in an almost complete Fontan palliation, redirecting blood from the superior vena cava as well as from the azygos vein to the pulmonary arteries and leaving only the hepatic veins draining into the systemic circulation. ${ }^{27} 28$

\section{FUNCTIONAL RESULT AND LONG TERM SEQUELAE}

Even in ideal Fontan candidates and after a "perfect" Fontan operation the instantaneous risk of cardiac failure and late death progressively increases with an $86 \%$ 5-year and $74 \%$ 10 -year survival. ${ }^{10}$ Long term results in patients after a lateral tunnel procedure documented a freedom from failure in $87 \%$ at 10 years. ${ }^{15}$ Early diagnosis and management of functional sequelae and complications associated with the Fontan physiology is required for improving the long term outcome and quality of life. Clinical assessment and echocardiographic evaluation, exercise testing, and Holter monitoring, as well as laboratory investigation are part of the routine postoperative surveillance. The timing of postoperative cardiac catheterisation and the additional value of computed tomography and magnetic resonance imaging need to be defined.

Arrhythmias are the major risk factor for morbidity and functional decline after the Fontan operation. The incidence of atrial arrhythmias ranges from $10 \%$ to $40 \% .^{25} 2930$ These include sinus node dysfunction associated with bradyarrhythmia as well as supraventricular tachycardias (junctional ectopic tachycardia, atrial ectopic tachycardia, intra-atrial reentry tachycardia).

Sinus node dysfunction is the most frequent dysrhythmia following total cavopulmonary connection caused by injury of the sinus node or disturbance of its blood supply. ${ }^{29-31}$ Freedom from bradyarrhythmia has recently been estimated to be $83 \%$ at 5 years and $73 \%$ at 10 years. ${ }^{15}$ Junctional rhythm and loss of atrioventricular synchrony result in reduction of cardiac output. Finally sinus node dysfunction predisposes patients to atrial reentry tachycardias. ${ }^{30}$ If pacemaker insertion is necessary in patients with symptomatic bradycardia, pacing in the DDD mode is preferred, as it increases pulmonary venous return and improves cardiac output. ${ }^{29}$

Supraventricular tachycardia was reported with an incidence of 5.5\%. ${ }^{15}{ }^{29}$ The overall freedom from SVT-mainly intra-atrial reentry tachycardia-was $94 \%$ after 5 years and $90 \%$ after 10 years. ${ }^{15}$ Progressive distension and wall stress with atrial enlargement as well as the presence of intra-atrial suture lines (required in the lateral tunnel procedure) facilitate the development of atrial reentry tachycardia. ${ }^{32}$ Older age at operation and longer duration of follow up turned out to be associated with the development of intraatrial reentry tachycardia. ${ }^{30}$

Thromboembolic events (systemic venous and arterial) have been documented with an incidence of 3-20\% with an unknown ratio of asymptomatic patients. ${ }^{25} 3334$ Increased systemic venous pressure, stasis of flow within the systemic venous atrium and pulmonary circulation, and increased resting venous tone certainly contribute to the risk of thrombus formation. In addition liver dysfunction and protein losing enteropathy may induce changes of synthesis of pro- and anticoagulant factors resulting in an unpredictable imbalance of the coagulation and fibrinolytic system. ${ }^{35-38}$ There is no consensus, however, concerning the postoperative mode and duration of prophylactic anticoagulation, since no controlled randomised studies have been performed comparing different therapeutic strategies. Routine anticoagulation with coumadin is performed by some institutions irrespective of the type of the modified Fontan procedure and potential risk factors. ${ }^{25} 33$ Many centres however recommend acetylsalicylic acid for uncomplicated patients with total cavopulmonary connection, while coumadin is reserved for children with additional risk factors as arrhythmia, protein losing enteropathy, or ventricular dysfunction. ${ }^{39}$

Protein losing enteropathy (PLE) may present with variable clinical manifestation ranging from significant morbidity to mild hypoproteinemia. It occurs weeks to years after Fontantype operations with an incidence of up to $13 \%{ }^{40}$ and a mortality after 10 years as high as $56 \%{ }^{41}$ Typical clinical features include pleural effusions, ascites, oedema, or chronic diarrhoea associated with a decrease of serum protein and $\gamma$ globulin, loss of lymphocytes, and an increase of stool $\alpha_{1}$ antitrypsin level. PLE may lead to an acquired combined immunodeficiency predisposing to infections. ${ }^{42}$ The pathogenesis of PLE is still unknown. Various risk factors have been discussed, including chronically increased systemic venous pressure with lymphangiectasis and activation of the renin-angiotensin system due to low cardiac output with increased levels of angiotensin II. $^{41}$ Management strategies for PLE include dietary modifications (eliminating long chain triglycerides), initiation of anticongestive therapy, and administration of steroids or high molecular weight heparin. In patients with haemodynamic deterioration and poor response to anticongestive therapy, cardiac catheterisation with creation of an atrial fenestration may be an additional option; the final option is heart transplantation..$^{40}$

Hepatic dysfunction may result from chronically increased systemic venous pressure and hepatic venous congestion, resulting in replacement of hepatocytes with fibrous tissue

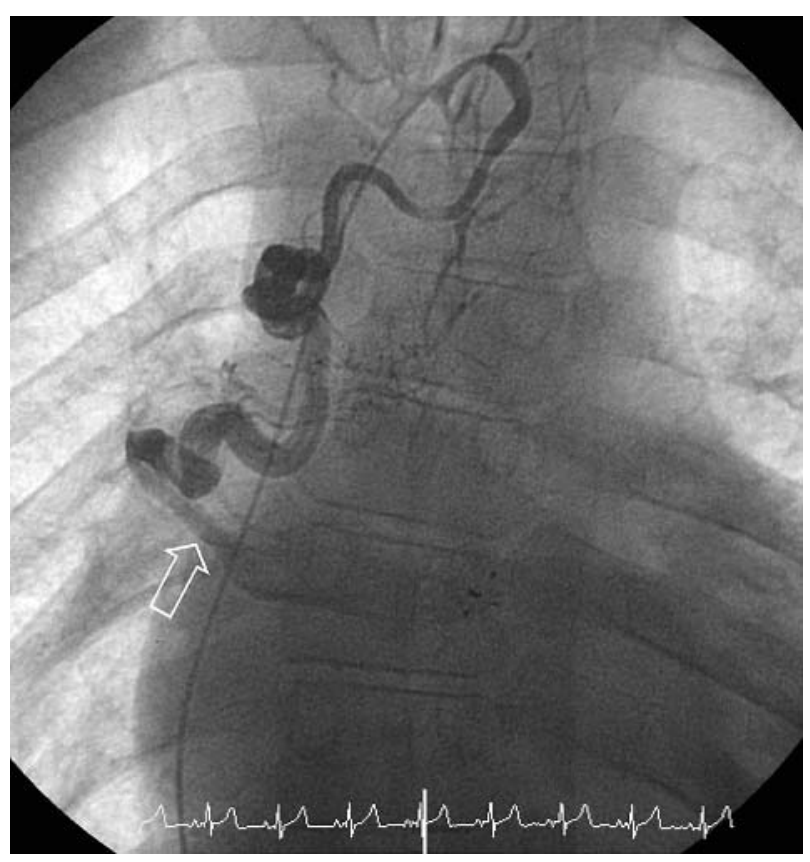

Figure 4 Selective injection of contrast into a tortous systemic venous channel originating from the innominate vein draining into the right upper pulmonary vein (arrow). 
and cirrhosis. ${ }^{44}$ In the majority of patients however, serum aminotransferase levels were normal or only mildly increased during long term follow up. Gamma-glutamyl transpeptidase levels were frequently mildly increased, whereas bilirubin was normal in all patients studied. ${ }^{36} 44$

Progressive cyanosis after Fontan operations should prompt a detailed search for abnormal systemic venous channels by angiographic evaluation of the supra- and infradiaphragmatic systemic veins. These collateral venous channels may terminate on a pulmonary vein or into the left atrium, causing functional right to left shunt. They may present as a (preoperatively undiagnosed) left superior caval vein draining into the coronary sinus or as intrahepatic communications shunting to a hepatic vein draining directly to the pulmonary venous atrium. ${ }^{45}{ }^{46}$ Various other venous channels may develop at different vascular levels by dilatation of preexisting venous channels. In the majority of cases the anomalous veins can be occluded with interventional catherisation $^{47} 48$ (fig 4).

The development of pulmonary arteriovenous malformations has been described in up to $25 \%$ of patients following a Glenn anastomosis leading to progressive cyanosis and exercise intolerance; these have been attributed to exclusion of hepatoenteric flow from the pulmonary circulation. ${ }^{28} 4950$ Therapeutic options in patients with pulmonary arteriovenous malformations are limited as these present often multiple and diffuse. ${ }^{49-51}$ Recent reports suggest, however, that reversal of pulmonary arteriovenous malformations is possible following redirection of hepatic venous flow to the pulmonary circulation $^{49}$ (fig 5).

Cardiorespiratory response to exercise in patients after Fontan procedure is abnormal and determined by significantly reduced oxygen uptake, subnormal heart rate at peak exercise, reduced aerobic capacity, minute ventilation, and tidal volume with a restrictive pattern of lung function. ${ }^{52} 53$

Patients with a functionally univentricular heart are at risk for neurological, cognitive, and psychological impairment before and after the Fontan procedure. Preoperatively there is often a duct dependent systemic or pulmonary circulation in a state of prolonged cyanosis or congestive heart failure. Only a few

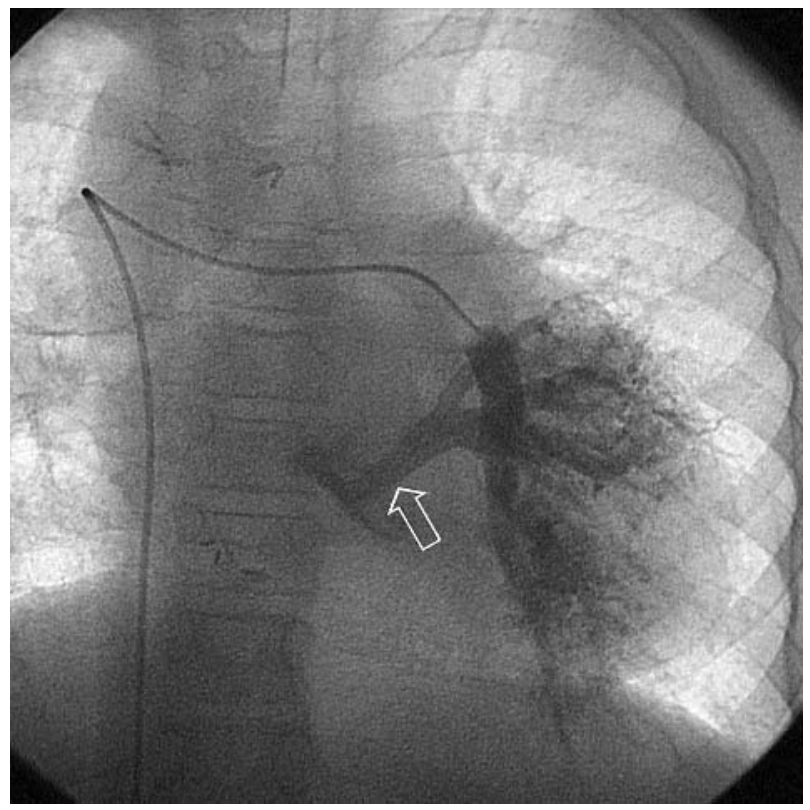

Figure 5 Pulmonary arteriovenous malformation in the right lung in a patient after a Kawashima-type operation (selective injection of contrast into the distal left pulmonary artery and simultaneous opacification of the left pulmonary veins (arrow)). studies have focused on neurodevelopmental testing, behavioural evaluation, and imaging of the central nervous system after the Fontan procedure. Intelligence scores and achievement testing scores were found to be in the normal range, but as a group the Fontan patients had significantly lower scores than the general population. ${ }^{54-56}$

\section{FAILURE OF THE FONTAN CIRCULATION, HEART TRANSPLANTATION}

The most common manifestations of failing Fontan physiology are atrial dysrhythmia, protein losing enteropathy, thromboembolic complications, progressive cyanosis, and exercise intolerance. So far there are no diagnostic tools which allow early prevention of declining univentricular circulation. Although refinement of preoperative selection and exclusion criteria has certainly improved the results, there still remains a continuing decrement of functional status during long term follow up. In this situation both Fontan take-down (conversion into bidirectional Glenn anastomosis) and orthotopic heart transplantation entails substantial early mortality. ${ }^{58}$ There are only limited experiences in Fontan take-down surgery; as this procedure was found to carry a high mortality it was felt to give only a brief delay before orthotopic heart transplantation becomes necessary as a rescue therapy in patients with failing Fontan circulation. ${ }^{57} 58$

\section{CONCLUSIONS}

Following major improvements of the surgical technique, modified Fontan operations represent a well accepted treatment for separation of pulmonary and systemic circulation in children with functionally univentricular hearts. Optimisation of flow dynamics was achieved by introduction of total cavopulmonary anastomosis, which can be performed either as a lateral tunnel or as an extracardiac conduit procedure. Staging the Fontan procedure by a bidirectional cavopulmonary anastomosis with early relief of volume load on the single ventricle and later completion of the Fontan circulation reduced the perioperative risk. Exercise tolerance of these patients remains reduced, however, due to characteristics of the Fontan circulation with increased systemic venous pressure, non-pulsatile pulmonary artery flow, and reduced preload to the systemic ventricle accompanied by subnormal heart rate at peak exercise. Despite reduced operative mortality there remains a worrying decrement during long term follow up due to sequelae and complications of the univentricular circulation. These include atrial dysrhythmias, thromboembolic events, development of hepatic dysfunction, protein losing enteropathy, or myocardial dysfunction. These problems document the obvious need for regular long term surveillance of these patients and prospective follow up studies.

\section{Authors' affiliations}

R Kaulitz, M Hofbeck, Department of Pediatric Cardiology and Pediatric Intensive Care Medicine, Tuebingen University Hospital, Germany

Competing interests: none declared

\section{REFERENCES}

1 Driscoll DJ, Offord K, Feldt R, et al. Five- to fiffeen-year follow-up after Fontan operation. Circulation 1992;85:469-96.

2 Azakie A, Merklinger SL, Williams WG, et al. Improving outcomes of the Fontan operation in children with atrial isomerism and heterotaxy syndromes. Ann Thorac Surg 2001;72:1636-40.

3 Stamm C, Friehs I, Duebener LF, et al. Improving results of the modified Fontan operation in patients with heterotaxy syndrome. Ann Thorac Surg 2002;74:1967-77.

4 Jonas RA, Lang P, Hansen D, et al. First stage palliation of hypoplastic left heart syndrome: the importance of coarctation and shunt size. J Thorac Cardiovasc Surg 1986;92:6-13. 
5 Sano S, Kawada M, Yoshida H, et al. Norwood procedure in hypoplastic left heart syndrome. Jpn J Thorac Cardiovasc Surg 1998;46:1311-16.

6 Fontan F, Kirklin KW, Fernandez G, et al. Outcome after a "perfect" Fontan operation. Circulation 1990;81:1520-36.

7 Maitiau A, Geva T, Colan SD, et al. Bulboventricular foramen size in infants with double inlet left ventricle or tricuspid atresia with transposed great arteries. J Am Coll Cardiol 1992;19:142-8.

8 Norwood WI, Jacobs ML. Fontan's operation in two stages. Am J Surg 1993;166:548-51.

9 Jacobs ML, Rychik J, Rome JJ, et al. Early reduction of the volume work of the single ventricle: the hemi-Fontan operation. Ann Thorac Surg 1996;62:456-61.

10 Fontan F, Baudet E. Surgical repair of tricuspid atresia. Thorax $1971 ; 26: 240-8$.

11 Biörk VO, Olin CL, Bjarke BB, et al. Right atrial-right ventricular anastomosis for correction of tricuspid atresia. J Thorac Cardiovasc Surg 1979;77:452-8.

12 Kreutzer G, Galindez E, Bono H, et al. An operation for the correction of tricuspid atresia. J Thorac Cardiovasc Surg 1973;66:613-21.

13 DeLeval MR, Kliner P, Gewillig $M$, et al. Total cavopulmonary connection: a logical alternative to atriopulmonary connection for complex Fontan operations. J Thoracic Cardiovasc Surg 1988;96:682-95.

14 Jonas RA, Castaneda AR. Modified Fontan procedure: atrial baffle and systemic venous to pulmonary artery anastomotic techniques. J Cardiac Surg 1988;3:91-6.

15 Stamm G, Friehs I, Mayer JE, et al. Long-term results of the lateral tunnel Fontan operation. J Thorac Cardiovasc Surg 2001;121:28-41.

16 Gentles TL, Mayer JE, Gavreau K, et al. Fontan operation in five hundred consecutive patients: factors influencing early and late outcome. J Thorac Cardiovasc Surg 1997; 114:376-91.

17 Hashimoto K, Kurosawa H, Tanaka K, et al. Total cavopulmonary connection without the use of prosthetic material: technical considerations and hemodynamic consequences. J Thorac Cardiovasc Surg 1995;1 10:625-32.

18 Choussat $\mathrm{P}$, Fontan $\mathrm{F}$, Besso $\mathrm{P}$, et al. Selection criteria for Fontan's operation In: Anderson R, Shineborne E, eds. Pediatric cardiology. New York: ChurchillLivingstone, 1977:559-60.

19 Bridges ND, Mayer JE, Lock JE, et al. Effect of baffle fenestration on outcome of the modified Fontan operation. Circulation 1992;86:1762-9.

20 Sommer RJ, Recto M, Golinko R, et al. Transcatheter coil occlusion of surgical fenestration after Fontan operation. Circulation 1996;94:249-52.

21 Lloyd TR, Rydberg A, Ludomirsky A, et al. Late fenestration closure in the hypoplastic left heart syndrome: comparison of hemodynamic changes. Am Heart J 1998;136:302-6.

22 Kopf GS, Kleinman CS, Hijazi ZM, et al. Fenestrated Fontan operation with delayed transcatheter closure of atrial septal defect. J Thorac Cardiovasc Surg 1992;103:1039-48

23 Woods RK, Dyamenahalli U, Duncan BW, et al. Comparison of extracardiac Fontan techniques: pedicled pericardial tunnel versus conduit reconstruction. $J$ Thorac Cardiovasc Surg 2003;125:465-71.

24 Azakie A, McCrindle BW, Van Arsdell G, et al. Extracardiac conduit versus lateral tunnel cavopulmonary connections at a single institution: impact on outcomes. J Thorac Cardiovasc Surg 2001;122:1219-28.

25 Shirai LK, Rosenthal DN, Reitz BA, et al. Arrhythmias and thromboembolic complications after the extracardiac Fontan operation. J Thorac Cardiovasc Surg 1998; 115:499-505.

26 Vouhe PR. Fontan completion: intracardiac tunnel or extracardiac conduit? Thorac Cardiovasc Surg 2001;49:27-9.

27 Kawashima Y, Kitamura S, Matsuda H, et al. Total cavopulmonary shunt operation in complex cardiac anomalies: a new operation. J Thorac Cardiovasc Surg 1984;87:74-81

28 Srivastava D, Preminger T, Lock JE, et al. Hepatic venous blood and the development of pulmonary arteriovenous malformations in congenital heart disease. Circulation 1995;92:1217-22.

29 Cohen MI, Wernovsky G, Vetter VL, et al. Sinus node function after a systematically staged Fontan procedure. Circulation 1998;98(suppl II):352-8.

30 Fishberger SB, Wernovsky G, Gentles T, et al. Factors that influence the development of atrial flutter after the Fontan operation. J Thorac Cardiovasc Surg 1997; 113:80-6.

31 Manning PB, Mayer JE, Wernovsky G, et al. Staged operation to Fontan increases the incidence of sinoatrial node dysfunction. J Thorac Cardiovasc Surg 1996;111:833-40.

32 Durongpisikul K, Porter C, Cetta F, et al. Predictors of early- and late-onset supraventricular tachyarrhythmias after Fontan operation. Circulation 1998;98:1099-1107.
33 Balling G, Vogt $M$, Kaemmerer $H$, et al. Intracardiac thrombus formation after the Fontan operation. J Thoarc Cardiovasc Surg 2000; 119:745-52.

34 Fyfe DA, Kline CH, Sade RM, et al. Transesophageal echocardiography detects thrombus formation not identified by transthoracic echocardiography after the Fontan operation. J Am Coll Cardiol 1991; 18:1733-7.

35 Rauch R, Ries M, Hofbeck M, et al. Hemostatic changes following the modified Fontan operation (total cavopulmonary connection). Thromb Haemost 2000:83:678-82.

36 Kaulitz R, Luhmer I, Bergmann F, et al. Sequelae after modified Fontan operation: postoperative haemodynamics and organ function. Heart 1997;58:154-9.

37 Odegaard C, McGowan FX, Zurakowski D, et al. Procoagulant and anticoagulant factor abnormalities following the Fontan procedure: increased factor VIII may predispose to thrombosis. J Thorac Cardiovasc Surg 2003;125:1260-7.

38 Jahangiri $M$, Shore $D$, Kakkar $V$, et al. Coagulation factor abnormalities after the Fontan procedure and its modifications. J Thorac Cardiovasc Surg 1997; 113:989-92.

39 Coon PD, Rychik J, Novello RT, et al. Thrombus formation after the Fontan operation. Ann Thorac Surg 2001;71:1990-4.

40 Feldt RH, Driscoll DJ, Offord KP, et al. Protein-losing enteropathy after the Fontan operation. J Thorac Cardiovasc Surg 1996; 1 12:672-80.

41 Mertens L, Hagler DJ, Saver U, et al. Protein-losing enteropathy after the Fontan operation: an international multicenter study. J Thorac Cardiovasc Surg 1998;115:1063-73

42 Chakrabarti S, Keeton BR, Salmon AP, et al. Acquired combined immunodeficiency associated with protein losing enteropathy complicating Fontan operation. Heart 2003;89:1130-1.

43 Freedom RM, Hamilton R, Yoo S, et al. The Fontan procedure: analysis of cohorts and late complications. Cardiol Young 2000;10:307-31.

44 Narkewicz M, Sondheimer HM, Ziegler JW, et al. Hepatic dysfunction following the Fontan procedure. J Pediatr Gastroenterol Nutr 2003;36:352-7.

45 Gatzoulis MA, Shinebourne EA, Redington AN, et al. Increasing cyanosis early after cavopulmonary connection caused by abnormal systemic venous channels. Br Heart J 1995:73:182-6.

46 McElhinney DB, Reddy M, Tworetzky W, et al. Incidence and implications of systemic to pulmonary collaterals after bidirectional cavopulmonary anastomosis. Ann Thorac Surg 2000;69:1222-8.

47 Stümper O, Wright JGC, Sadiq M, et al. Late systemic desaturation after total cavopulmonary shunt operations. Br Heart J 1995;74:282-6.

48 Kaulitz R, Ziemer G, Paul Th, et al. Fontan-type procedures: residual lesions and late interventions. Ann Thorac Surg 2002;74:778-85.

49 Shah MJ, Rychik J, Fogel MA, et al. Pulmonary AV malformations after superior cavopulmonary connection: resolution after inclusion of hepatic veins in the pulmonary circulation. Ann Thorac Surg 1997;63:960-3

50 Lamour JM, Hsu DT, Kichuk MR, et al. Regression of pulmonary arteriovenous malformations following heart transplantation. Pediatr Transpl 2000;4:280-4.

51 Knight WB, Mee RBB. A cure for pulmonary arteriovenous fistulas? Ann Thorac Surg 1995;59:999-1001.

52 Fredriksen PM, Therrien J, Veldtman G, et al. Lung function and aerobic capacity in adult patients following modified Fontan procedure. Heart 2001;85:295-9.

53 Durongpisikul K, Driscoll DJ, Mahoney DW, et al. Cardiorespiratory response to exercise after modified Fontan operation: determinants of performance. J Am Coll Cardiol 1997;29:785-90.

54 Goldberg CS, Schwartz EM, Brunberg JA, et al. Neurodevelopmental outcome of patients after the Fontan operation: a comparison between children with hypoplastic left heart syndrome and other functional single ventricle lesions. J Pediatr 2000;137:646-52.

55 Wernosky G, Stiles KM, Gauvreau K, et al. Cognitive development after the Fontan operation. Circulation 2000;102:883-9.

56 Mahle WT, Clancy RR, Moss EM, et al. Neurodevelopmental outcome and lifestyle assessment in school-aged and adolescent children with hypoplastic left heart syndrome. Pediatrics 2000;105:1082-9.

57 Michielon G, Parisi F, Squitieri C, et al. Orthotopic heart transplantation for congenital heart disease: an alternative for high-risk Fontan candidates? Circulation 2003;108(suppl I):11140-9.

58 Knott-Craig CJ, Danielson GK, Schaff HV, et al. The modified Fontan operation. J Thorac Cardiovasc Surg 1995;109:1237-43. 